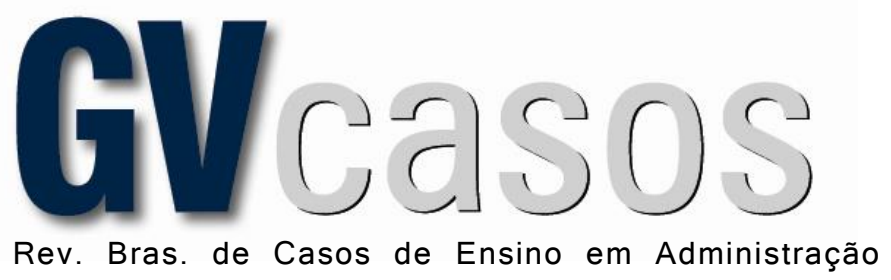

DOI: http://dx.doi.org/10.12660/gvcasosv5n1c6

\title{
IMPLANTAÇÃO DE SISTEMAS EMPRESARIAIS: UM CASO DE RESILIÊNCIA OU TEIMOSIA?
}

Introducing business systems: a case of resilience or stubbornness?

EDUARDo FERREIRA FranCo - eduardo.franco@ gmail.com

Escola Politécnica da Universidade de São Paulo - São Paulo, SP, Brasil

Submissão: 12/12/2014 | Aprovação: 12/05/2015

\section{Resumo}

A sobrevivência de uma empresa familiar de grande porte depende do sucesso de um processo de reestruturação. Apesar disso, a iniciativa foi até aqui conduzida como um projeto da área de TI e não da empresa.

O caso aborda um contexto comum vivenciado por empresas de diferentes portes e segmentos que decidem lançar-se no desafio de aumentar sua eficiência e competitividade, tendo como um dos pilares desse processo a implantação ou revitalização de sistemas de informação.

Palavras-chave: Empresa familiar, Gestão de empresas, Tecnologia da informação, Estratégia empresarial, Sistemas de informação.

\begin{abstract}
The survival of a large family enterprise depends on the success of a restructuring process. Despite this, the initiative has so far been conducted as an IT area project and not a company project.

The case deals with a common context experienced by different size companies and segments that decide to launch themselves headfirst into the challenge of increasing their efficiency and competiveness, having as one of the pillars of this process the introduction or revitalization of its information systems.
\end{abstract}

Keywords: Family Enterprise; Business Management; Information Technology; Business Strategy; Information Systems.

\section{Contexto inicial}

A Edifícios S.A. é uma empresa de grande porte que atua no segmento de construção civil, mais especificamente na construção de empreendimentos imobiliários residenciais populares, e com atuação em toda a extensão territorial brasileira. Ela foi fundada em meados da década de 1970 e, ao longo dos seus 40 anos, manteve uma estrutura familiar de administração com seus fundadores ainda no comando executivo.

No ano de 2011, após quatro décadas de atuação, a diretoria tomou a decisão de iniciar um processo de transição do comando da empresa para uma segunda geração. Em uma reunião entre acionistas e diretores, decidiu-se por iniciar um processo de reestruturação ampla que se estenderia pelos anos subsequentes. 
IMPLANTAÇÃO DE SISTEMAS EMPRESARIAIS: UM CASO DE RESILIÊNCIA OU TEIMOSIA?

Eduardo Ferreira Franco

Para eles, a empresa precisaria enfrentar alguns problemas crônicos para conseguir perenizar o negócio e conduzir a transição desejada com sucesso. Por exemplo:

- Inchaço administrativo sem melhora da qualidade dos controles e serviços;

- Promoções desatreladas de méritos, que conduziram profissionais sem qualificação a cargos de liderança;

- Contratação de profissionais, sem critérios de avaliação definidos e adequados, que não produzem resultados desejados;

- Transferência de profissionais para outros setores quando deveriam ser substituídos, uma vez que já demonstraram incapacidade;

- Empresa defasada quando comparada aos concorrentes com relação a rotinas administrativas e utilização de sistemas de informação;

- Diminuição do comprometimento de setores importantes na hierarquia e camadas mais baixas, dificultando a implantação de inovações e melhorias e tornando frequentes os casos de complacência.

O início desse processo ocorreu ainda em 2011, quando foi contratada uma consultoria para iniciar um diagnóstico da situação da empresa, identificar as fraquezas, consolidar as boas práticas referentes ao conhecimento tácito do planejamento e gestão dos empreendimentos (construído ao longo das quatro décadas pelos atuais diretores e, com a saída da atual diretoria, este conhecimento precisaria ser mantido na empresa), propor ações e elaborar um planejamento de médio e longo prazos para executar as mudanças necessárias.

Os objetivos principais traçados nesse planejamento eram:

- Empresa com alto grau de comprometimento geral de seus funcionários;

- Escritório central enxuto;

- Equipe qualificada, focada em inovações tecnológicas e organizacionais, implantações, orientações, treinamento e controles;

- Canteiro de obras assumindo o máximo possível das tarefas administrativas para reduzir o custo fixo;

- Política de ganhos e incentivos baseada em metas e resultados;

- Descentralização e informatização da empresa.

Esses desafios demandariam alterações estruturais em todas as áreas da empresa e contemplariam: alteração no organograma, criação de novos departamentos, criação de novos cargos e novos níveis hierárquicos para preencher uma lacuna da média gerência na estrutura administrativa (até o momento, havia apenas encarregados que respondiam diretamente aos diretores), desenvolvimento de novas competências (liderança, comunicação etc.) e a contratação de novos profissionais.

Entre as posições que seriam preenchidas com contratações de profissionais vindos do mercado, estava a posição de gerência da área de Informática. Nesse contexto, inicia-se este caso de ensino.

\section{Início dos trabalhos}

No início de 2012, após meses de entrevistas e muita reflexão, Francisco, com então 40 anos, aceitou o desafio de assumir o cargo de gerente de TI na empresa Edifícios S.A. e enfrentar os desafios propostos pelos diretores para a reestruturação da empresa. A área de TI era subordinada à diretoria administrativa e financeira, que tinha Pedro como diretor e a quem Francisco responderia.

Apesar de ter conhecido grande parte da diretoria da empresa durante o período de entrevistas e conversado sobre as expectativas com relação aos resultados esperados, a equipe que lideraria, o contexto e a situação atual da empresa, Francisco ainda não sabia ao certo o que encontraria no seu primeiro dia de trabalho. 
IMPLANTAÇÃO DE SISTEMAS EMPRESARIAIS: UM CASO DE RESILIÊNCIA OU TEIMOSIA?

Eduardo Ferreira Franco

Em seu primeiro contato, sua percepção foi de uma empresa com um quadro de funcionários com muito tempo de casa, e a maioria deles tinha na empresa a única experiência profissional. Muitas pessoas começaram a carreira na empresa como auxiliares nos canteiros de obras e foram "crescendo" com o passar do tempo.

A configuração do escritório também chamou sua atenção. Era um espaço físico bastante segmentado, com divisórias entre departamentos, existia pouca ou nenhuma comunicação entre as áreas e as pessoas. O organograma da empresa era verticalizado, caracterizando uma estrutura organizacional funcional (apresentado no Anexo 1), com cada departamento respondendo a uma diretoria específica e pouca colaboração e projetos entre os departamentos.

Também chamou-lhe a atenção o fato de que grande parte da comunicação era feita por circulares em papel, que tramitavam pela empresa por meio de mensageiros. Esse mesmo sistema de "malote" era utilizado como meio de comunicação entre os processos com a circulação de informações impressas entre obras e departamentos do escritório central.

Francisco vislumbrou diversas oportunidades de melhorias e desafios que aquele cenário proporcionava para a área de TI e, somando com o apoio que havia recebido da diretoria da empresa para realizar as transformações necessárias, o cenário de trabalho parecia promissor.

O contato com a área de TI também foi interessante. A empresa como um todo via o departamento como um centro de manutenção de microinformática. Qualquer dispositivo eletrônico que apresentasse algum problema era remetido para a área. Essas atividades consumiam a maior parte do tempo da equipe e a impediam de dedicar-se a outras atividades, o que era desmotivador. A equipe até então era composta de quatro pessoas, dois analistas e dois assistentes; com a chegada de Francisco, seriam cinco.

Uma parte do desafio seria transformar a área de TI de uma área técnica e operacional em uma área estratégica, que atendesse as novas demandas da empresa e das áreas de negócio. Francisco precisaria alterar o foco da equipe para trabalhos de maior valor agregado, aquilo que traria valor para a empresa e reconhecimento para a área.

Seriam necessárias mudanças na estrutura do departamento de TI, como contratação de novos profissionais, desenvolvimento da equipe, revisão de políticas e procedimentos, criação de células especializadas (infraestrutura, projetos, segurança etc.) e terceirização de algumas rotinas.

\section{$O$ primeiro sistema de gestão integrado}

Antes da chegada de Francisco à Edifícios S.A., havia ocorrido, em meados de 2000, uma iniciativa para implantar o primeiro sistema de gestão integrada (ERP). Essa iniciativa não decorreu de uma necessidade de integrar a empresa e buscar eficiência das áreas, mas como uma alternativa para substituir o sistema utilizado pelo departamento de Contabilidade, que seria descontinuado devido ao "bug do milênio".

A implantação desse sistema não veio acompanhada de uma revisão sistemática dos processos, controles, pessoas ou até mesmo uma reflexão das oportunidades que surgiriam. Esse projeto foi percebido e conduzido pela empresa meramente como uma substituição da ferramenta de trabalho da área de Contabilidade.

Após a entrada em operação do ERP e com o crescimento acelerado da empresa, o departamento de Contabilidade começou a ficar sobrecarregado. Esse departamento era responsável por todos os lançamentos de documentos fiscais, movimentações financeiras, conciliações e consolidação de declarações legais. Para evitar tornar-se um gargalo, a contabilidade começou a transferir algumas atividades feitas no sistema para outras áreas, como os lançamentos de notas fiscais, que foram repassados para o departamento Financeiro, e posteriormente para os empreendimentos.

Com o passar do tempo, o sistema foi crescendo de maneira desorganizada e desestruturada. Não houve uma preocupação com padronização de processos, com a qualificação dos usuários, nem 
mesmo com a infraestrutura para suportar o sistema. Todo o conhecimento havia sido adquirido e transmitido informalmente, com base na observação de outros usuários mais experientes trabalhando. Esse crescimento desestruturado ocorreu durante 10 anos. Ao longo desse período, o sistema era utilizado meramente para fins regulatórios e apenas por pessoas ligadas às rotinas operacionais da empresa. As informações gerenciais eram feitas com relatórios paralelos elaborados pelo próprio diretor administrativo e financeiro, Pedro.

Até o momento, a diretoria não via necessidade de realizar investimentos em TI, nem mesmo no seu ERP. Nesse período, a empresa vinha apresentando resultados positivos que atendiam as expectativas com relação a margem e geração de caixa, assim, aquilo que existia até então bastava para a empresa funcionar.

\section{Reconhecendo o ambiente}

Os seis primeiros meses de trabalho de Francisco foram dedicados a um processo de integração para conhecer e ambientar-se ao contexto em que estava sendo inserido. Nesse período, ele também elaborou o planejamento das atividades que levaria adiante para atuar em um dos pilares identificados pela diretoria no processo amplo de reestruturação da empresa, que consistia na modernização e informatização das rotinas.

Para isso, visitou todos os departamentos e alguns empreendimentos, observou as rotinas, tentou identificar os controles e informações importantes em cada área, a interação dos usuários com o sistema, registrou expectativas, críticas e sugestões em relação ao departamento de TI e o atual sistema utilizado.

Não existiam processos formalmente padronizados e documentados, eles eram regidos pelo uso, costume e conhecimento tácito dos funcionários mais antigos. Essas características dificultavam o treinamento de novos funcionários, impediam iniciativas de melhoria continua, perpetuavam vícios e deficiências e, além de tudo, constituíam um obstáculo para implantação de qualquer sistema integrado.

Chamou a atenção de Francisco o fato de os controles gerenciais da empresa serem feitos com ferramentas e informações paralelas, ignorando aquelas existentes no sistema utilizado até então. Existiam planilhas para controle e apuração de retenções de pagamento de fornecedores, ficha de contratação de novos funcionários, planilha de apuração de cartão de ponto dos funcionários, notas fiscais e pagamentos eram lançados no sistema e em um controle paralelo que gerava o controle de movimento diário de pagamento, ordens de pagamentos eram inseridas manualmente no site do banco etc.

Quanto aos empreendimentos, eles funcionavam como filiais da empresa. Grande parte deles tinha CNPJ próprio e reportavam para o escritório central mensalmente um relatório gerencial com seu desempenho. Esse relatório continha informações referentes ao avanço físico, fluxo de caixa, prestação de contas do fundo fixo, previsões etc.

Esses relatórios eram alimentados com dados provenientes de controles paralelos realizados nas obras. Não existia uniformidade e padrão nos conceitos adotados para a consolidação desses indicadores gerenciais, e cada obra adotava um critério próprio (existiam desencontros relacionados a conceitos como: regime de caixa, competência, fato gerador, antecipação e retenções de impostos, adiantamentos, mútuos etc.).

O departamento de Planejamento do escritório central era responsável por consolidar as informações fornecidas pelos empreendimentos e elaborar um relatório de desempenho da carteira de obras. Essa compilação consistia nos indicadores de desempenho da diretoria de obras, que tinha como diretor Ernesto, e era responsável pelos empreendimentos e departamento de Planejamento.

A diretoria administrativa financeira, que tinha Pedro como responsável, compilava seus indicadores com os demonstrativos de fluxo e disponibilidade de caixa que o departamento Financeiro construía com base no controle paralelo que mantinha dos pagamentos e extratos 
IMPLANTAÇÃO DE SISTEMAS EMPRESARIAIS: UM CASO DE RESILIÊNCIA OU TEIMOSIA? Eduardo Ferreira Franco

bancários, e os balancetes e demonstrativos de resultado de exercício (DRE), preparados pelo departamento Contábil com base nas informações conciliadas disponíveis no sistema.

Como esses indicadores, tinham fontes e conceitos diferentes, representavam controles gerenciais divergentes e muitas vezes incoerentes. Os sócios e executivos da empresa não tinham segurança nas informações que recebiam para tomar decisões estratégicas para novos investimentos.

Essas divergências também traziam reflexos no dia a dia dos departamentos da empresa. Muitos conflitos ocorriam na tentativa de encontrar os "culpados" pelos erros frequentes que eram identificados. Os atritos faziam com que as rotinas da empresa ficassem truncadas, fossem pouco eficientes e eliminavam qualquer tipo de cooperação e sinergia que pudesse existir.

Francisco notou grande resistência em dois departamentos que eram chave para o sucesso da reestruturação do sistema de informação: Contabilidade e Suprimentos. O primeiro recebia informações de todas as áreas da empresa e consolidava demonstrativos com finalidades fiscal e gerencial. O segundo controlava toda a estrutura de produtos e serviços para realizar a solicitação de materiais, pedidos de compras, recebimento de materiais, controle de estoque, histórico de preços para elaboração de orçamentos de novos empreendimentos e ainda continha o elo de ligação para gerar as informações de acordo com o plano contábil.

Quando esteve nesses dois departamentos, ele notou que eram os que tinham a maior predominância de pessoas com muito tempo de casa e que estavam acomodadas com a atual estrutura e rotina de trabalho. Durante as visitas, essas pessoas demonstraram pouco interesse em compartilhar informações, conhecimentos, críticas e sugestões. A impressão que Francisco teve era de que pairava a vontade de manter as coisas como estavam, afinal de contas, estavam confortáveis com a situação e tinham domínio das rotinas e informações com que trabalhavam. A permanência do status quo constituía a manutenção da posse das informações e políticas e, por consequência, da estrutura de poder da empresa.

Além das informações coletadas até então, Francisco decidiu realizar uma pesquisa junto aos funcionários da empresa para levantar a percepção que eles tinham com relação ao sistema utilizado e tirar suas próprias conclusões. Foram distribuídos formulários com perguntas fechadas e abertas, e o preenchimento era realizado de maneira anônima.

O público atingido pela pesquisa contemplou aproximadamente $40 \%$ de todo o efetivo administrativo da empresa e contou com representantes de todos os níveis hierárquicos (estratégico, tático e operacional). O Anexo 2 apresenta alguns resultados obtidos nessa pesquisa.

Por meio dessa pesquisa, ficou claro para Francisco que o sistema era visto como algo importante pelos usuários para o desempenho das atividades diárias (75\%), mesmo atendendo parcialmente as necessidades (69\%) e com grande parte dos usuários não tendo sido treinada adequadamente (75\%). Mas seria preciso atender as expectativas deles quanto à necessidade de ter acesso às informações (26\% falta de relatório) e desenvolver um fluxo contínuo de treinamento (16\% complexidade e $32 \%$ conhecimento).

\section{Começo das mudanças}

Passado o período de integração, Francisco iniciou, no segundo semestre de 2012, diálogos com o atual fornecedor do ERP e com empresas que atuavam no mesmo segmento e utilizavam sistemas de informação. Em paralelo, ele também começou a prospectar outros fornecedores de sistemas ERP.

Era preciso identificar se os problemas enfrentados pela Edifícios S.A. eram um caso particular, consistiam em uma fase de maturação e transição pela qual outras empresas também passaram, eram causados pela baixa qualidade e aderência do software adquirido, por erros cometidos no projeto de implantação ou até mesmo pelos escassos investimentos realizados durante o ciclo de vida do sistema já em operação.

Após a fase investigatória, Francisco, Pedro e os demais diretores decidiram trocar o atual sistema utilizado, mas manter o fornecedor, que detinha uma grande participação do mercado 
IMPLANTAÇÃO DE SISTEMAS EMPRESARIAIS: UM CASO DE RESILIÊNCIA OU TEIMOSIA?

Eduardo Ferreira Franco

brasileiro de ERPs. Diversas construtoras que Francisco visitou e que utilizavam esse novo sistema demonstraram ter obtido êxito na implantação e estavam satisfeitas com o desempenho pósimplantação. O próprio fornecedor posicionava o novo sistema para o segmento de construção civil, enquanto o sistema utilizado até então era voltado principalmente para o segmento manufatureiro.

Outro fator que influenciou a decisão foi a viabilidade da empresa em arcar com o valor previsto para o investimento direto no primeiro ano, que representava por volta de $10 \%$ do overhead de 2013, mas estava coerente com os valores que as empresas visitadas informaram ter investido em suas iniciativas.

Francisco, juntamente com Pedro, conduziu as negociações com o fornecedor, e iniciaram os preparativos para o projeto de substituição do ERP. Esses preparativos, a articulação com as demais áreas para disponibilizarem recursos para o projeto e a sensibilização da empresa estenderam-se ao longo dos quatro primeiros meses de 2013.

Nesse período, foi criada uma estrutura de governança composta por um núcleo de gerenciamento do projeto, onde participavam Francisco, como gerente do projeto por parte da Edifícios S.A., em conjunto com um representante da equipe de implantação do fornecedor, líderes das áreas impactadas pelo projeto, e Pedro, que atuaria como o representante da alta administração e sponsor do projeto. Esse grupo se reuniria semanalmente para analisar o andamento e os riscos do projeto.

Uma segunda estrutura, o comitê executivo, composta pelos diretores da empresa (incluindo Pedro e Ernesto), Francisco e o representante do fornecedor, também foi criada. Esse comitê se reuniria mensalmente para avaliar o andamento do projeto e tratar as questões que não foram resolvidas pelo núcleo de gerenciamento do projeto.

Com a data de início definida, o projeto foi, então, comunicado de maneira ampla para toda a empresa pelo próprio presidente. Em linhas gerais, os objetivos diretos do projeto de implantação do novo sistema consistiam em:

- Definir um modelo de operação, administrativo e financeiro;

- Revisar, modelar e formalizar os fluxos dos processos;

- Recomendar indicadores de desempenho dos processos;

- Melhorar a qualidade e confiabilidade das informações;

- Melhorar a integração e interface dos processos;

- Evitar customizações no sistema; e

- Trazer mais eficiência operacional para a empresa.

A partir daí, foi alocada uma equipe exclusivamente para o projeto que era composta por representantes de todas as áreas afetadas, tanto no escritório central quanto nas obras. Algumas dessas pessoas estariam alocadas em tempo integral (a grande maioria), e outras parcialmente.

O kick-off do projeto da TI ocorreu no fim de abril de 2013, e os trabalhos foram divididos em cinco fases, conforme apresentado no Anexo 3.

A fase de modelagem e revisão dos processos foi dividida em duas frentes de trabalho, que eram compostas por seis e sete grupos de processos cada (Anexo 4). Cada grupo de processo tinha como responsável o líder da área, em conjunto com seu respectivo diretor, e participava uma equipe de trabalho formalmente nomeada que era composta por representantes das áreas que faziam interface com os processos. Essas equipes reuniam-se periodicamente para debater e revisar os 120 processos e definir os futuros indicadores de monitoramento do desempenho.

Um segundo grupo de atividades foi conduzido paralelamente pelo núcleo de Recursos Humanos, que também estava em fase embrionária na empresa. Ele atuaria nas ações voltadas a gestão da mudança organizacional decorrentes da revisão de processos e implantação do novo sistema. O cronograma resumido das fases identificadas no Anexo 3, acrescidas das atividades desse segundo grupo, é apresentado no Anexo 5. 
O projeto envolveu diretamente uma equipe de 20 consultores externos e 50 funcionários do quadro da empresa. A estimativa do esforço empregado no projeto foi de aproximadamente 25 mil homens-hora (sem contabilizar o tempo destinado ao treinamento dos usuários finais).

Com os processos definidos e aprovados pelos responsáveis e pelos diretores das áreas, teve início a etapa da análise da aderência ao novo sistema. Uma das diretrizes pactuadas no início do projeto foi evitar as customizações no sistema. Essa diretriz foi estabelecida para evitar que o sistema virasse uma "colcha de retalhos" e que vícios e práticas ineficientes do passado fossem incorporadas ao novo sistema.

Dessa análise, resultou uma relação de customizações que era composta por relatórios gerenciais e algumas rotinas específicas da empresa. Em reunião do comitê executivo do projeto, foi tomada a decisão de incorporar o desenvolvimento dos relatórios ao escopo do projeto e deixar as demais modificações para uma segunda fase, pois concluíram que elas não impactariam a operação da empresa, mas poderiam colocar em risco a viabilidade do prazo do projeto.

No início de agosto de 2013, foi iniciada a fase de implantação do sistema. Francisco dividiu o trabalho da área de TI em duas frentes: a migração dos dados do antigo sistema e a parametrização do novo sistema. A migração dos dados foi uma frente conduzida exclusivamente pela área de TI (depois de definido pelas áreas de negócio o que deveria ser migrado), enquanto a parametrização foi conduzida pelos consultores do fornecedor e usuários-chave das áreas de negócio, mas acompanhada por um recurso da área de TI.

Nessa etapa, os consultores capacitavam aqueles que atuariam como usuários-chave das áreas para que eles realizassem as configurações e, ao mesmo tempo, validassem o comportamento do sistema conforme as especificações dos processos desenhados nas etapas anteriores. Havia uma preocupação para que o conhecimento fosse transferido e absorvido pelas pessoas que operariam o sistema no dia a dia e que, após a entrada em operação do sistema, seriam responsáveis pela manutenção e suporte aos usuários finais.

Apesar do cronograma apertado e alguns atrasos na fase de implantação, no início de dezembro, todos os cadastros e configurações haviam sido realizados, os dados selecionados do sistema antigo haviam sido migrados e os testes preliminares realizados pelos usuários-chave, concluídos.

Em dezembro de 2013, foram realizados os últimos testes integrados. Durante esse período, as áreas executaram em paralelo as rotinas críticas da empresa que não poderiam sofrer qualquer tipo de interrupção, como folha de pagamento, declarações fiscais etc.

Além dos testes, foi elaborado um plano de contingência descrevendo os procedimentos alternativos que deveriam ser adotados caso ocorresse algum problema ou situação para a qual não houvesse solução.

No primeiro dia de trabalho de 2014, tanto o escritório central como todos os canteiros de obras estavam operando o novo sistema. Nas primeiras semanas, houve problemas de todas as naturezas, mas nenhum deles foi crítico a ponto de parar as rotinas da empresa.

\section{Tempestades à vista}

Passadas as primeiras semanas de 2014, a frequência dos incidentes foi diminuindo e a situação, ficando sob controle. Francisco, então, propôs a Pedro dar continuidade ao projeto com o início da segunda fase para não deixar a equipe mobilizada se dissipar. Era preciso tratar os assuntos que foram postergados para depois da virada do sistema e aparar arestas que foram identificadas. Pedro aceitou a proposta, e, assim, iniciou-se a segunda fase do projeto, juntamente com um programa de melhoria contínua dos processos recém-implantados.

Os dois imaginavam que, com o uso e conhecimento do sistema, outras melhorias ainda surgiriam e essa iniciativa manteria as decisões tomadas até então na pauta das discussões diárias que permeavam a empresa toda. 
IMPLANTAÇÃO DE SISTEMAS EMPRESARIAIS: UM CASO DE RESILIÊNCIA OU TEIMOSIA?

Eduardo Ferreira Franco

Nessa segunda etapa, o núcleo do gerenciamento do projeto foi mantido com reuniões quinzenais para avaliar o andamento das ações e analisar as necessidades emergentes, mas o quórum foi formado apenas por representantes do escritório central. A diretoria, por sua vez, não viu a necessidade de manter o comitê executivo. Quando necessário, os assuntos seriam tratados na reunião de diretoria, na qual participavam Pedro e Ernesto.

Ainda no primeiro semestre de 2014, alguns problemas crônicos começaram a aparecer. Muitos usuários estavam reticentes em mudar a forma de trabalho a que estavam habituados e adotar os novos processos. Os treinamentos previstos inicialmente acabaram não sendo conduzidos da forma adequada. Muitos usuários foram treinados por telefone e outros aprenderam pela observação do trabalho dos então usuários-chave.

Devido a essa resistência, muitos começavam a atribuir erros e problemas operacionais ao sistema como justificativa para voltarem a trabalhar na sistemática antiga. Entrava em operação o modelo: "criar dificuldades para vender facilidades".

A implantação do sistema eliminou algumas flexibilidades que existiam quando as atividades e processos não eram formalizados ou eram executados em ferramentas paralelas. Com a automação e a informatização, alguns processos ficaram engessados e desapareceram os "jeitinhos".

As mudanças introduzidas faziam com que a irritação por parte dos usuários crescesse sensivelmente, principalmente nas obras. Alguns processos começaram a ser abandonados sob a alegação de que o sistema não funcionava, era lento, a burocracia era excessiva e que a carga de trabalho havia crescido exageradamente.

Os recebimentos de mercadorias, que deveriam ser precedidos por ordens de compra, passaram a ser recebidos pelos almoxarifados das obras sem nenhuma formalização prévia. As solicitações de pagamentos de fornecedores chegavam ao escritório central no dia do vencimento. $\mathrm{O}$ processo de faturamento, que no redesenho havia sido integrado ao orçamento da obra com o intuito de permitir que controles gerenciais comparassem receita e despesa, não funcionou como esperado. Os responsáveis pelas rotinas delegaram suas atividades para terceiros que desconheciam o assunto, $\mathrm{o}$ que quase causou a interrupção do faturamento da empresa e deu origem à "crise das faturas".

Apesar dos esforços de Francisco para manter o foco e interesse dos envolvidos na segunda fase do projeto para mantê-la na pauta da alta administração, a equipe começou a se dispersar com o surgimento de outras prioridades. As atenções estavam voltadas para o aumento da concorrência, a desaceleração do setor e a piora dos resultados da empresa (Anexos 6, 7 e 8).

Com a mudança de foco, começava a se consolidar na empresa o entendimento de que a responsabilidade pelo projeto e a operação do sistema era exclusivamente da área de TI. Essa visão aumentava a pressão sobre a área, principalmente Francisco e Pedro, para que provesse soluções para todos os problemas que surgiam (sendo eles relacionados ao sistema, definições de negócio, falta de treinamento ou resistência dos usuários).

O momento mais traumático do primeiro ano de operação do novo sistema ocorreu no segundo semestre de 2014, quando as expectativas criadas junto à diretoria de obras (Ernesto) e aos gerentes dos empreendimentos não viraram realidade no prazo esperado. Francisco e Pedro haviam subestimado o risco associado à fragilidade dos recém-criados processos de orçamento, planejamento e controle de obras e da área de planejamento. Esses processos ainda não tinham maturidade suficiente para ser informatizados e estavam em uma fase de aprendizagem, adaptação e acomodação dentro da empresa.

Para implantação dos novos processos de planejamento, foram selecionadas quatro obras para atuarem como pilotos. O critério para seleção dessas obras foi estabelecido por Ernesto e consistia naquelas que ainda estavam na fase inicial e eram localizadas na mesma cidade do escritório central (o que facilitaria qualquer necessidade de deslocamento para treinamento e apoio).

Existia a expectativa, por parte de Ernesto e alguns gerentes de obra, de que o sistema faria o trabalho relativo ao planejamento e controle de obras de maneira quase autônoma. Para realizar o reporte mensal ao escritório central, bastaria clicar um botão do novo sistema para extrair os 
IMPLANTAÇÃO DE SISTEMAS EMPRESARIAIS: UM CASO DE RESILIÊNCIA OU TEIMOSIA? Eduardo Ferreira Franco

relatórios gerenciais. Mesmo que implícita, existia a visão de que a responsabilidade das pessoas seria reduzida e o sistema assumiria parte da inteligência do negócio. A automação dessas atividades tornaria possível atingir, em um curto prazo, o objetivo de reduzir os custos fixos da empresa.

O resultado foi desastroso: ao invés de facilitar, o sistema passou a ser um tormento para os usuários das obras. Os orçamentos, que consistiam em um dos principais componentes do sistema, foram feitos sem critério. Sob a pressão de Ernesto para cumprir o prazo estabelecido para entrega, as obras pilotos terceirizaram sua elaboração sem levar em consideração as especificações técnicas e os projetos executivos. A intenção era cumprir o prazo independentemente da qualidade para se eximir da responsabilidade pelo eventual atraso do projeto.

As previsões referentes aos histogramas de mão de obra, materiais, serviços, custos, receitas e fluxo de caixa eram calculadas com base em informações incorretas contidas nos orçamentos. Essas previsões, em conjunto com os dados de receitas e despesas que não tinham conceitos importantes alinhados, abasteciam os relatórios gerencias com informações incoerentes, tornando-os de certo modo inúteis.

Quando esses novos relatórios começaram a ser extraídos e enviados ao departamento de Planejamento para consolidar os indicadores da diretoria de obras, um princípio de conflito surgiu entre Pedro e Ernesto. A diferença entre os indicadores das duas diretorias, ao invés de se reduzir, como era a expectativa inicial de todos, cresceu vertiginosamente.

Ernesto, sob pressão dos demais diretores, devido à divergência dos indicadores, argumentava que o sistema não funcionava, que ele não foi parametrizado da forma que havia sido especificado na fase de revisão de processos, e os departamentos Financeiro e Contábil estavam consolidando relatórios equivocados. Os números entregues pelas obras, mesmo com as dificuldades encontradas e sacrifício de sua equipe, estavam corretos.

Nesse momento, Pedro comprou a briga de Francisco e contra-argumentou que a qualidade daquilo que era inserido no sistema determinava a qualidade de suas saídas, mas sua opinião foi ofuscada no calor das discussões.

As alterações introduzidas pela diretoria administrativa financeira para implementar as travas orçamentárias sistêmicas dos orçamentos de obras e buscar a descentralização do escritório central, que eram um desejo antigo da empresa, exigiam um dinamismo para o qual ela não estava preparada. Era preciso ter equipes nas obras para revisar qualquer alteração no cronograma e orçamento a fim de evitar que os controles se tornassem obsoletos e restringissem o andamento da obra (uma vez que qualquer estouro de custo ou prazo bloquearia novos lançamentos de pedidos ou notas fiscais). Como não era possível, muito trabalho administrativo começou a acumular-se nas obras (por exemplo, ordens de compras, lançamentos de notas, admissão de funcionários etc.), o que gerou gargalos operacionais que começaram a impactar o dia a dia do escritório central.

Nesse momento, foi a vez de Pedro pressionar Ernesto para que as equipes de obras atendessem os processos e políticas estabelecidos. As áreas de escritório central estavam sobrecarregadas devido ao grande volume de trabalhos de "última hora" que surgiam diariamente. Essa sobrecarga demandava seguidos dias de trabalhos em jornadas extraordinárias para atender os prazos (inclusive nos finais de semana).

Ernesto tentava argumentar que os problemas e gargalos eram causados pelo sistema, pelas novas burocracias criadas e rotinas repassadas do escritório central para as obras, mas dessa vez foi Pedro quem não deu ouvidos.

Nesse impasse, Ernesto convocou uma reunião com sua equipe de gerentes solicitando que eles elaborassem um relatório retratando como o novo sistema não atendia suas necessidades e os problemas que vinham enfrentando diariamente em suas obras. Ele pediu também que eles levantassem outros sistemas utilizados por empresas do mesmo segmento por onde trabalharam anteriormente ou tivessem conhecidos que trabalhassem.

Com essas informações, Ernesto consolidou uma proposta solicitando a substituição do sistema implantado e apresentou-a em uma reunião de diretoria. 
IMPLANTAÇÃO DE SISTEMAS EMPRESARIAIS: UM CASO DE RESILIÊNCIA OU TEIMOSIA?

Eduardo Ferreira Franco

Nesse cenário de conflito, a percepção do presidente era de que faltavam parcerias, não existia trabalho colaborativo, nem mesmo compromisso com o resultado coletivo para a empresa superar os desafios que surgiam nesse momento de transição. $\mathrm{O}$ ano de 2014 foi caracterizado por muitos conflitos na empresa que não eram apenas originados pela substituição do ERP. Existiam outros fatores que contribuíam para a tensão e estresse no ambiente, como áreas recém-criadas, como Planejamento e Recursos Humanos, que introduziram novas rotinas, a desaceleração do setor (Anexo 7) fazia crescer a pressão sobre as obras para apresentar melhores resultados e o próprio resultado da empresa nos últimos exercícios (Anexo 8).

O presidente da empresa resolveu, então, solicitar à área de Recursos Humanos uma pesquisa de engajamento e clima organizacional, onde foram coletados relatos anônimos de funcionários da empresa (Anexo 9).

\section{Momento de decisão}

Em janeiro de 2015, o presidente da empresa decidiu convocar uma reunião para tratar o assunto que vinha crescendo e ganhando repercussão na empresa entre a diretoria administrativa e financeira e a diretoria de obras: trocar o sistema recém-implantado ou realizar novos investimentos no sistema atual? Independentemente da decisão tomada, a discussão das mudanças necessárias na condução do projeto também seria abordada nessa reunião.

Além do presidente da empresa, participariam dessa reunião o diretor de obras (Ernesto), o diretor administrativo e financeiro (Pedro), os gerentes das áreas do escritório central (inclusive Francisco) e os responsáveis pelas quatro obras que atuaram como pilotos nesse primeiro ano.

Ao receber a convocação, Francisco reuniu-se com Pedro para alinhar o material que levariam para a reunião. Desse encontro, Francisco ficou incumbido de consolidar uma apresentação contendo as diferentes alternativas que discutiram, juntamente com uma análise dos pontos fortes e fracos de cada uma delas, e a recomendação pela decisão que acordaram.

Como era de se esperar, instantes antes de a reunião começar, o clima era de tensão, e um princípio de discussão entre Ernesto e Pedro teve de ser contido pelos demais presentes. Com a chegada do presidente, teve início a reunião e, junto com ela, a discussão calorosa foi retomada. Cada lado buscava defender sua posição, apresentando justificativas, apontando problemas do outro e identificando culpados, mas nenhuma proposta efetiva era apresentada. Ao perceber que a reunião estava saindo do controle, o presidente, em um tom de voz mais elevado, pediu que fosse seguida a pauta da reunião e, pela sequência preestabelecida, seria a vez de Francisco iniciar a sua exposição e defender sua proposta de trabalho... 


\section{Anexo 1}

Organograma simplificado da empresa Edifícios S.A.

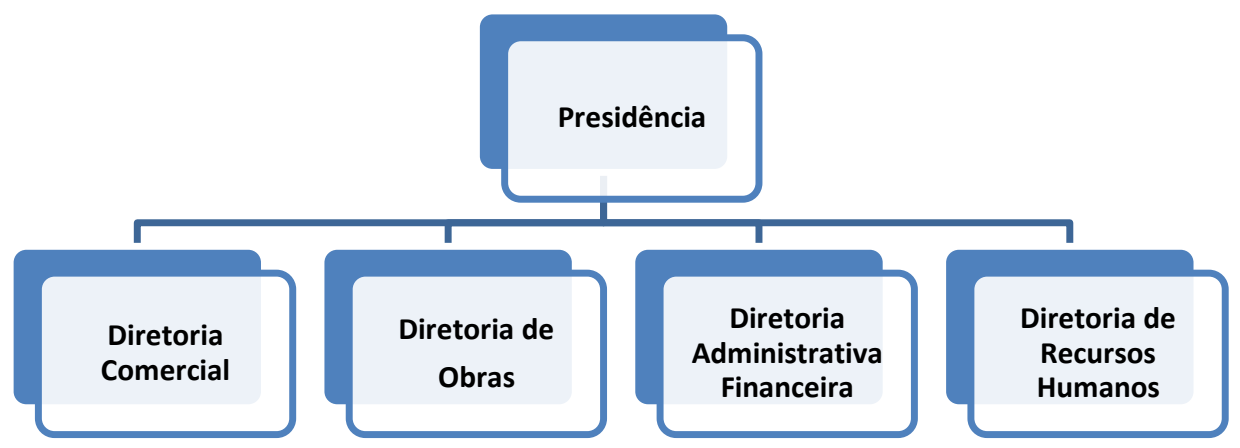

\section{Anexo 2}

Resultado da pesquisa realizada junto aos usuários do sistema

Recebeu treinamento formal?

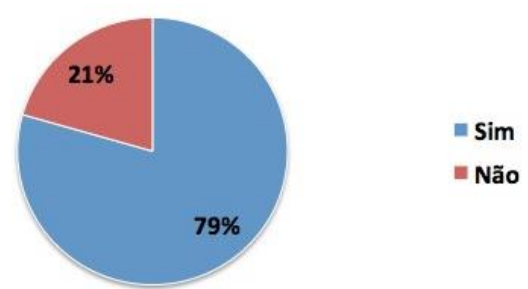

Qual a importância no seu dia a dia?

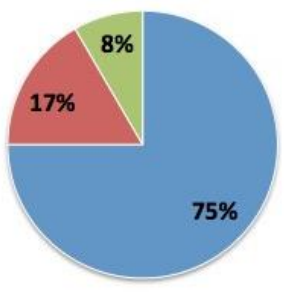

O sistema atende suas necessidades?

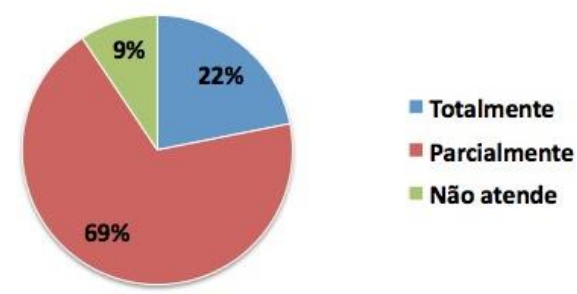

Qual o maior obstáculo para o uso?

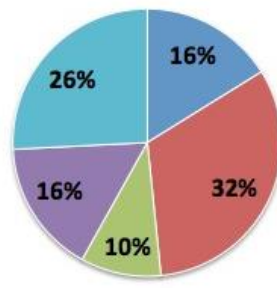

- Complexidada

winhecimento

in Infraestrutura

" Não aderente

- Falta de relatórios 
IMPLANTAÇÃO DE SISTEMAS EMPRESARIAIS: UM CASO DE RESILIÊNCIA OU TEIMOSIA?

Eduardo Ferreira Franco

\section{Anexo 3}

Fases do projeto de substituição do sistema de gestão

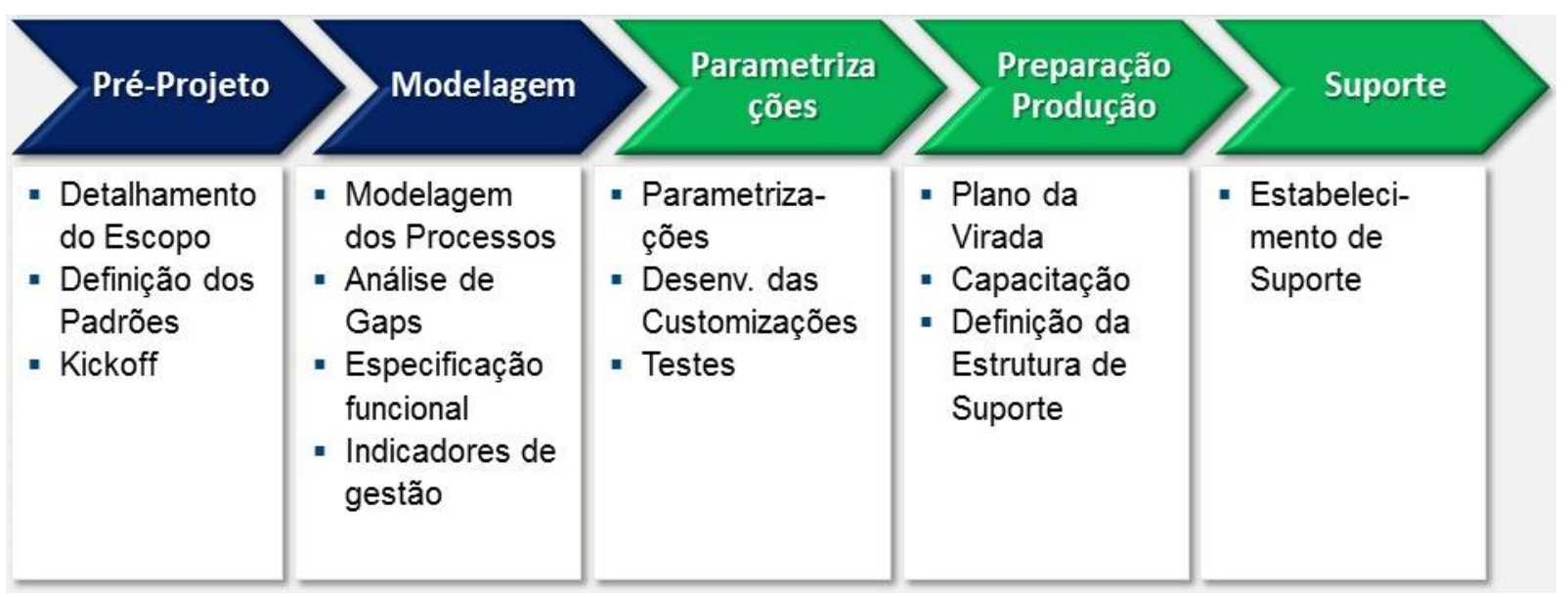

\section{Anexo 4}

Divisão das frentes de trabalho da fase de modelagem de processos

\section{Frente 1}

- Gestão de Pessoal

- PCO (Planejamento, Controle Orçamentário e Custos) das obras

- SESMT (Segurança e Medicina do Trabalho)

- Compras e avaliação de fornecedores

- Planejamento de estoque

- Recebimento de materiais

\section{Frente 2}

- Contabilidade e Ativo fixo

- Faturamento e Contas a receber

- Contas a pagar

- Tesouraria

- Livros Fiscais

- Processo de Qualidade (Auditorias, Controle de Documentos e NãoConformidades)

- Gestão de Contratos (Clientes e Fornecedores) 
IMPLANTAÇÃO DE SISTEMAS EMPRESARIAIS: UM CASO DE RESILIÊNCIA OU TEIMOSIA?

Eduardo Ferreira Franco

\section{Anexo 5}

Resumo consolidado do cronograma do projeto de implantação do ERP

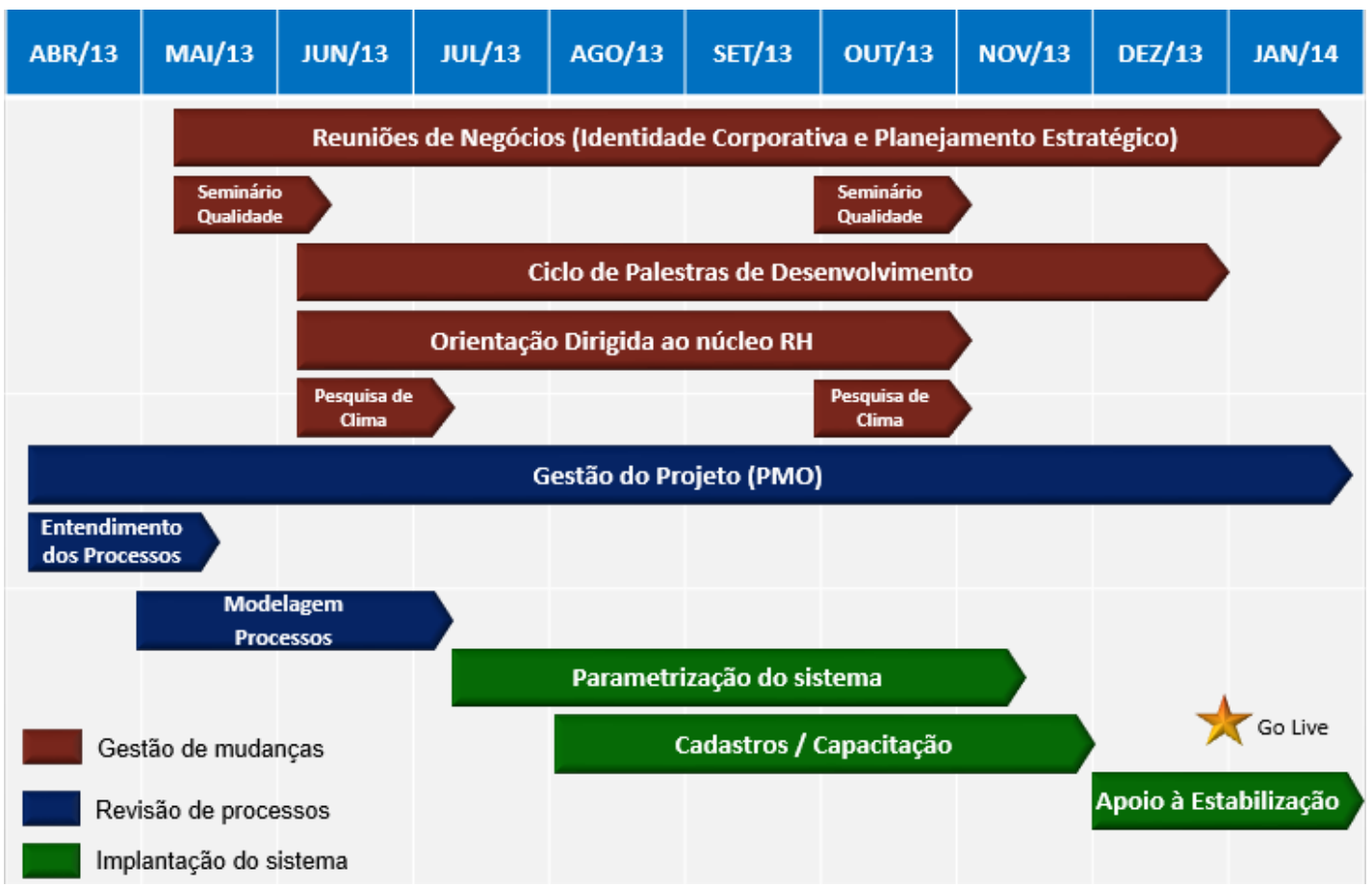

Anexo 6

Número de estabelecimentos na construção civil (Brasil e grandes regiões)

\begin{tabular}{c|c|c|c|c|c|c|c}
\hline \multicolumn{1}{|c|}{ ANO } & $\mathrm{n}^{\circ}$ de estabelecimentos \\
\hline Região Norte & $2007^{*}$ & $2008^{*}$ & $2009^{*}$ & $2010^{*}$ & $2011^{*}$ & $2012^{*}$ & $2013^{*}$ \\
\hline Região Nordeste & 4.775 & 5.602 & 6.093 & 6.916 & 7.725 & 8.203 & 9.020 \\
\hline Região Sudeste & 18.226 & 20.466 & 22.719 & 27.300 & 31.069 & 34.301 & 37.124 \\
\hline Região Sul & 58.649 & 65.797 & 70.288 & 80.853 & 90.989 & 94.675 & 100.527 \\
\hline Região Centro-Oeste & 26.664 & 32.046 & 35.009 & 41.621 & 47.637 & 50.834 & 54.944 \\
\hline TOTAL BRASIL & 117.460 & 135.164 & 147.175 & 172.703 & 195.954 & 208.537 & 223.773 \\
\hline
\end{tabular}

Fonte: RAIS 2000-2013/MTE. Elaboração: Banco de Dados - CBIC.

* De acordo com a nova Classificação Nacional de Atividades Econômicas (CNAE) 2.0 de novembro/2006. 


\section{Anexo 7}

\section{Nível de atividade efetivo em relação ao usual}

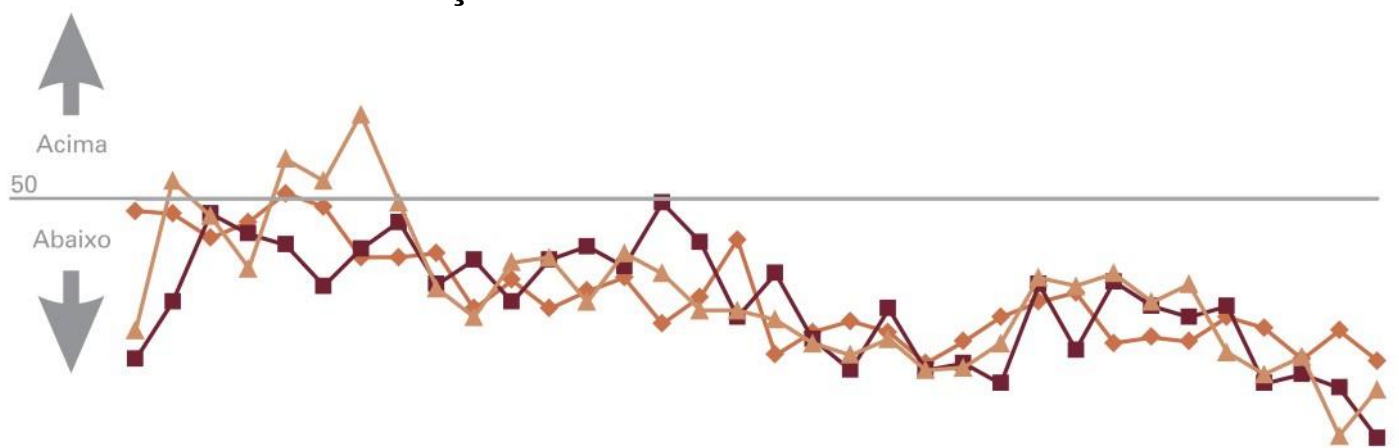

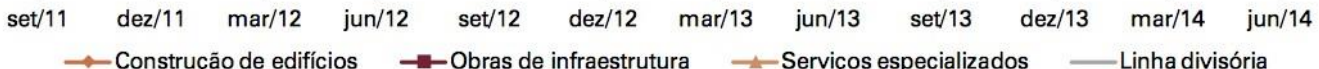

Fonte: Sondagem da Construção Civil - CNI/CBIC.

Indicador varia no intervalo de "0" a "100".

Valores acima de "50" indicam atividade acima do usual.

Nota: na edição n. 6, ano 5, de julho de 2014 da Sondagem da Construção Civil do CNI em parceria com o $\mathrm{CBIC}^{1}$, o seguinte retrato foi descrito:

Os três setores da construção registraram queda na atividade em junho. Contudo, a queda foi mais disseminada nas empresas do setor Obras de infraestrutura: indicador de 41,7 pontos, contra 46,3 para Construção de edifícios e 43,0 para Serviços especializados.

Esse é também o setor mais desaquecido. O indicador do nível de atividade efetivo em relação ao usual situou-se em 39,1 pontos, enquanto que em Construção de edifícios o indicador foi de 42,6 pontos e em Serviços especializados foi de 41,3 pontos.

Com relação aos indicadores financeiros, a situação é negativa nos três setores. A margem de lucro e a situação financeira foram avaliadas como insatisfatórias no trimestre, sendo essa percepção mais intensa em Serviços especializados e Obras de infraestrutura.

O acesso ao crédito foi avaliado como difícil no trimestre também pelos três setores. No setor Serviços especializados o indicador situou-se em 34,9 pontos, sendo o setor que percebe maior dificuldade. O setor Construção de edifícios apresentou indicador de 38,7 pontos, enquanto que Obras de infraestrutura apontou indicador de 37,4 pontos.

\footnotetext{
${ }^{1}$ Acessado pelo endereçohttp://www.portaldaindustria.com.br/publicacoes-e-estatisticas/publicacoes/ em $1 / 10 / 2014$.
} 


\section{Anexo 8}

\section{Indicadores anuais da Edifícios S.A.}

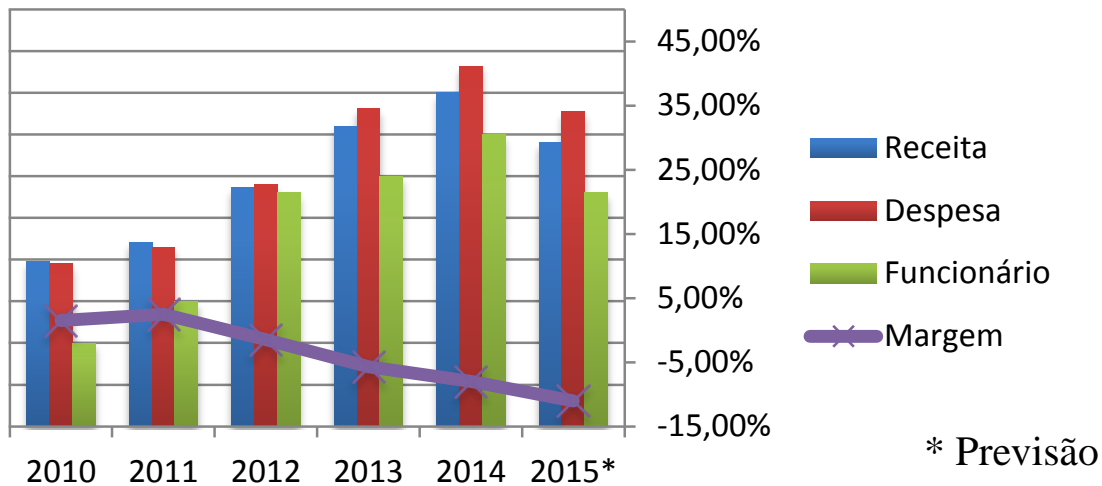

\section{Anexo 9 \\ Amostra de respostas da pesquisa de engajamento e clima organizacional}

Exemplos de declarações coletadas anonimamente dos funcionários da empresa Edifícios S.A., referentes à percepção do clima existente na empresa no momento em que foi realizada a pesquisa.

Existem alguns departamentos, principalmente aqueles em que os líderes são funcionários mais antigos na empresa, os quais, por diferentes razões (vaidades, inseguranças), entendem que o nível de colaboração necessário para determinada tarefa é determinado por eles próprios, ou seja, não compreendem que a empresa está passando por um processo de profunda transformação em que as pessoas terão que abrir mão de vontades (vaidades) próprias para atingir objetivos comuns.

Primeiramente, os problemas têm que ser reconhecidos. Independentemente do que a pessoa contribuiu no passado ou tempo de casa, quando houver um determinado problema com ela, esse problema não deve ser enviado diretamente para baixo do tapete. Esse tipo de atitude desmotiva o interesse na melhoria da empresa. Tem que ser demonstrado que o melhor para empresa não é o que ela acha, e sim o que toda corporação ACREDITA.

Como sugestão, os departamentos devem ser tratados de forma igual, pois todos têm sua importância dentro da organização. O procedimento de lançamento de notas deve ser revisto. Existe reunião de Diretoria, na minha opinião devemos criar reuniões gerenciais a fim de discutir necessidades e interface, com a presença de um diretor, para melhor aproximação.

Percebo que as pessoas têm uma resistência enorme as mudanças e novidades, como se tudo que fosse novo fosse ruim. Existem também muitas pessoas que têm privilégios e benefícios que outros não têm, o que acaba gerando desmotivação e falta de engajamento. 